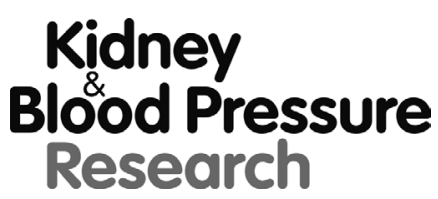

Kidney Blood Press Res 2018;43:1065-1074

DOI: 10.1159/000491057

Publisned online: 2 July, 2018

(C) 2018 The Author(s)

Published by S. Karger AG, Basel

Accepted: 20 June, 2018

This article is licensed under the Creative Commons Attribution-NonCommercial-NoDerivatives 4.0 International License (CC BY-NC-ND) (http://www.karger.com/Services/OpenAccessLicense). Usage and distribution for commercial purposes as well as any distribution of modified material requires written permission.

\title{
Applying Regional Citrate Anticoagulation in Continuous Renal Replacement Therapy for Acute Kidney Injury Patients with Acute Liver Dysfunction: a Retrospective Observational Study
}

\author{
Ying Yu Sheng Peng Zhongran Cen Jing Cai Wei Wang Ying Tang \\ Meng Du Zhanguo Liu Ping Chang \\ Department of ICU, Zhujiang Hospital, Southern Medical University, Guangzhou, Guangdong, China
}

\section{Key Words}

Citrate $\cdot$ CRRT $•$ Anticoagulant $•$ Liver dysfunction • AKI

\begin{abstract}
Background/Aims: Continuous renal replacement therapy (CRRT) is a treatment for acute kidney injury (AKI) patients. It has become a controversy about whether patients with liver dysfunction should perform CRRT with regional citrate anticoagulation (RCA). Methods: This retrospective observational study enrolled 145 AKI patients (275 CRRT sessions) who received CRRT with RCA and had no history of chronic liver disease. Circuit survival time, blood pressure, trans-membrane pressure (TMP), acid-base and electrolyte status were recorded and analyzed. The severity of liver dysfunction was determined by total bilirubin (TBil) and international normalized ratio (INR), while the accumulation degree of citrates was quantified by total/ ionized calcium ( $\mathrm{tCa} / \mathrm{iCa}$ ) raito. Results: Our results showed that there was no correlation of $\mathrm{tCa} / \mathrm{iCa}$ ratio with TBil or INR. And $\mathrm{tCa} / \mathrm{iCa}$ ratio was not related to the disturbances of $\mathrm{pH}$, lactates, sodium, magnesium, blood pressure or TMP despite that high $\mathrm{tCa} / \mathrm{iCa}$ ratios might be related to the decrease of circuit survival time. TBil did not correlate with the above indexes, except for lactates levels. INR did not correlate with the above indexes except for lactates levels and blood pressure. In addition, neither was TBil, INR, nor $\mathrm{tCa} / \mathrm{iCa}$ ratio, related with fatal outcomes (22.76\% of the patients). Conclusion: The present study demonstrated that, with proper monitoring and adjustment of citrates and calcium infusion, applying RCA in CRRT is reasonably safe for AKI patients with acute liver dysfunction, as long as circuit time stays below roughly 50 hours.




\section{Kidney Blood Pressure Research}

Yu et al.: Study of RCA in CRRT for AKI Patients with Acute Liver Dysfunction

\section{Introduction}

Acute kidney injury (AKI) is a common disease in intensive care units (ICU) with a high mortality rate [1]. For severe AKI patients, renal replacement therapy (RRT) is often applied to compensate for their kidney function. RRT can be performed either in a continuous way (CRRT) or an intermittent way (IRRT). CRRT is optimal for hemodynamically unstable patients [2], with possible effects on long-term recovery of kidney function [3, 4]. Moreover, CRRT is proven cost-effective than IRRT [4-6]. Thus CRRT has become the predominant form of RRT for critically ill patients [7]. CRRT was designed to run continuously more than 24 hours in order to provide a slow and uninterrupted clearance of the endogenous and exogenous toxins, and a homeostasis of acid-base, electrolyte, and volume [8].

Anticoagulation is required for extracorporeal circulation in CRRT. Most widely used anticoagulant is unfractionated heparin (UFH) [9]. However, this kind of anticoagulant could increase the risk of bleeding due to antithrombin consumption, especially in critically ill patients [10-12]. Moreover, heparin could generate deleterious effects on microcirculation, inflammation pathways, and phagocytotic clearance of dead cells [10]. Whereas, applying regional citrate anticoagulation (RCA) could avoid these problems. Citrates are infused before blood enters CRRT circuit. Then citrates inactivates the ionized calcium (iCa), the key component of coagulation, by combining with it. In contrast with systemic heparin anticoagulation, RCA shows a benefit of less bleeding, longer filter lifespan, and lower transfusion rates [13-15].

As a matter of fact, in line with KDIGO (Kidney Disease: Improving Global Outcomes) guidelines, citrates should be used in CRRT for all patients without contraindications and heparin for other patients [2]. The contraindications referred to liver diseases or shock states as the metabolism is compromised in such conditions, which could lead to the accumulation of citrates [16]. The clearance of citrates is predominantly in the hepatic citric acid cycle and partly in the skeletal muscle, but almost completely independent of renal function and urinary excretion $[17,18]$. Excessive amount of citrates could cause systemic ionized hypocalcemia, with a consequence of systemic hypocoagulability and decreased cardiac contractility, as well as hypotension induced by the decreased vascular tone [10]. Since available observational studies have shown different results [19-24], applying CRRT with RCA in patients with liver dysfunction remained controversial. Thus the present study was aimed to verify whether performing CRRT with RCA in AKI patients with acute liver dysfunction would lead to the assumed complications or adverse outcomes.

\section{Materials and Methods}

\section{Study cohort and exclusion criteria}

This retrospective observational study was approved by the Ethics Committee of Zhujiang Hospital (Southern Medical University, Guangzhou, China). Consents were obtained from the participants to participate and publish. All data were anonymized and de-identified before analysis. The medical records of AKI patients hospitalized in ICU of Zhujiang Hospital (Southern Medical University, Guangzhou, China), who were treated with CRRT using RCA during the time span from January 2014 to August 2015, were recorded. Any CRRT session with its duration less than 24 hours was excluded. We also excluded any cases with missing data regarding total bilirubin (TBil), international normalized ratio (INR), total calcium (tCa) or ionized calcium (iCa). In the study cohort, the liver dysfunction cases were all acute liver dysfunction, and mostly induced by septic shock.

\section{Collections of clinical data}

Clinical data were collected including age, gender, APACHE (acute physiology and chronic health evaluation) II score, diagnosis, fatal outcome as well as before and in the end of CRRT including TBil, INR, 


\section{Kidney Blood Pressure Research}

Yu et al.: Study of RCA in CRRT for AKI Patients with Acute Liver Dysfunction

blood urea nitrogen (BUN), the trans-membrane pressure (TMP), blood pressure, $\mathrm{pH}$, lactates, sodium, magnesium, tCa and iCa levels.

\section{Data categorization}

All cases were categorized according to the liver function, accumulation degree of citrates and hospitalization outcome. According to their median levels, all cases were divided on a fifty-fifty basis. The accumulation degree of citrates was measured by $\mathrm{tCa}$ /iCa ratio. According to its cut-off value 2.1, all cases were divided into two groups as the low citrate group ( $\mathrm{tCa} / \mathrm{iCa}$ ratio $<2.1$ ) and the high citrate group ( $\mathrm{tCa} /$ iCa ratio 22.1 ] [25]. Outcome was all-cause death.

\section{CRRT protocol}

The patients who developed AKI above stage II (mainly in stage III) according to KDIGO guidelines [2] were considered to receive CRRT. CRRT was performed in standard procedure, using Gambro Prismaflex, with the filter model AN69-M100. The effluent flow and mean blood flow rate were determined by the weight of the patient, respectively calculated as $35 \mathrm{~mL} /(\mathrm{h} \cdot \mathrm{kg})$ and $3 \mathrm{~mL} /(\mathrm{min} \cdot \mathrm{kg})$. The infusion rate of citrates was adjusted to maintain post-filter iCa levels in $0.25-0.45 \mathrm{mmol} / \mathrm{L}$. The infusion rate of $5 \%$ calcium chloride solution was adjusted according to the levels of iCa in blood (Supplemental Table 1), to maintain blood iCa levels in 1.0-1.2mmol/L. For all supplemental material see www.karger.com/doi/ 10.1159/000491057.

CRRT was stopped if the patient: 1) had an improvement on physical status; 2) died; 3) abandoned treatment; 4) was transferred to take exams; 5) had an obstruction in the effluent drainage; 6) showed a TMP higher than $300 \mathrm{mmHg}$.

\section{Data analysis}

SPSS 20.0 statistics software was used to analyze the data. All data were nonparametric, presented as median (lower quartile value; upper quartile value). Mann-Whitney-Wilcoxon tests were applied for two independent variables, while Kruskal-Wallis $\mathrm{H}$ test for three or more independent variables. Spearman correlation analysis was applied to analyze the bivariate relations. Pearson Chi-square test was applied to analyze categorical variables. $\mathrm{P}<0.05$ was considered statistically significant.

\section{Results}

\section{Descriptive cohort information}

A total of 145 patients were enrolled (providing 275 CRRT sessions), including 92 males and 53 females, aging from 13 to 88 years old, with a median of $59(48 ; 72)$ years old. The median APACHE II score was 28(23;35). 33 cases were categorized into the death group and 112 cases into the survival group (Table 1). The main reason for death was multiple organ dysfunction syndrome (MODS). And some other cases ended in abandonment of treatment because of economic pressure and poor prognosis.

There was no statistical difference in gender or age between the two levels of tCa/iCa ratio (both $\mathrm{p}>0.05$ ). Also, there was no statistical difference in age between the two levels of TBil ( $p>0.05)$, and no statistical difference in gender between the two levels of INR ( $p>0.05)$. However, the high TBil group consisted of more male patients than the low TBil group $(p=0.025)$, while the patients appeared generally older in the high INR group than the low INR group $(\mathrm{p}=0.037)$.

At the initiation of all CRRT sessions, the median level of blood creatinine was 241 $(120 ; 486) \mu \mathrm{mol} / \mathrm{L}$; and the median level of BUN was 19.25 (10.73;32.50) mmol/L. Among all 275 CRRT sessions, there were 66 sessions that ended with their TMP higher than $300 \mathrm{mmHg}$ and 6 sessions ended because of the obstruction in the effluent drainage. 


\section{Kidney Blood Pressure Research}

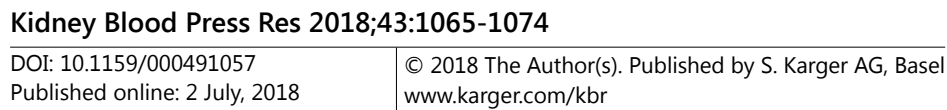
www.karger.com/kbr

Table 1. Descriptive cohort information. *APACHE II score: Acute physiology and chronic health evaluation II score. ${ }^{*}$ Low citrate group: Cases with $\mathrm{tCa} / \mathrm{iCa}$ ratio $<2.1$. ${ }^{*}$ High citrate group: Cases with $\mathrm{tCa} / \mathrm{iCa}$ ratio $\geq 2.1$. *Low TBil group: Cases with total bilirubin level $<13.20 \mu \mathrm{mol} / \mathrm{L} .{ }^{*} \mathrm{High}$ TBil group: Cases with total bilirubin level $\geq 13.20 \mu \mathrm{mol} / \mathrm{L}$. *Low INR group: Cases with international normalized ratio<1.29. *High INR group: Cases with international normalized ratio $\geq 1.29$. ${ }^{*} \mathrm{P}$ value: Mann-Whitney-Wilcoxon test was applied to compare age differences between the two groups. Pearson Chi-square test was applied to compare gender differences between the two groups. ${ }^{* *} \mathrm{P}<0.05$

\begin{tabular}{|c|c|c|c|c|c|}
\hline Characteristics & Case number & $\begin{array}{c}\text { Age } \\
\text { [median(quartiles)] }\end{array}$ & $\begin{array}{c}\text { Gender } \\
\text { [male/female] }\end{array}$ & $\begin{array}{l}\text { APACHE II score* } \\
\text { [median(quartiles)] }\end{array}$ & $\begin{array}{c}\text { Fatal outcome } \\
\text { [death/survival] }\end{array}$ \\
\hline All cases & 145 & $59(48 ; 72)$ & $92 / 53$ & $28(23 ; 35)$ & $33 / 112$ \\
\hline Low citrate group* & 85 & $58(48 ; 71)$ & $58 / 27$ & $25(21 ; 33)$ & $16 / 69$ \\
\hline High citrate group* & 60 & $60(48 ; 74)$ & $34 / 26$ & $25(21 ; 36)$ & $17 / 43$ \\
\hline P value* & & 0.422 & 0.156 & 0.586 & 0.228 \\
\hline Low TBil group* & 72 & $60(47 ; 74)$ & $39 / 33$ & $25(20 ; 35)$ & $16 / 56$ \\
\hline High TBil group* & 73 & $57(48 ; 69)$ & $53 / 20$ & $27(21 ; 33)$ & $17 / 56$ \\
\hline$P$ value & & 0.193 & $0.025^{* *}$ & 0.536 & 1.000 \\
\hline Low INR group* & 72 & $56(45 ; 69)$ & $41 / 31$ & $24(20 ; 33)$ & $13 / 59$ \\
\hline High INR group* & 73 & $63(51 ; 73)$ & $51 / 22$ & $29(22 ; 36)$ & $20 / 53$ \\
\hline $\mathrm{P}$ value & & $0.037^{* *}$ & 0.122 & 0.095 & 0.235 \\
\hline
\end{tabular}

The correlation of $\mathrm{tCa} /$ iCa ratio with TBil and INR

The correlation analysis showed that the $\mathrm{tCa} / \mathrm{iCa}$ ratio was not correlated with TBil level $(\mathrm{p}=0.122$, correlation coefficient $=-0.129$ ), nor INR level $(p=0.742$, correlation coefficient $=-0.028$ ).

\section{Comparing different} variables in the end of CRRT between the two levels of $\mathrm{tCa} / \mathrm{iCa}$ ratio

Using $\mathrm{tCa} / \mathrm{iCa}$ ratio of 2.1 as the threshold [25], all cases were categorized into two groups. Different variables recorded in the end of CRRT were compared between these two groups (Table 2). Among them, no significant difference was found in the levels of blood pressure, TMP, $\mathrm{pH}$, lactates, sodium or magnesium (all $\mathrm{P}>0.05$ ), whereas the circuit survival time in the low citrate group was longer $(\mathrm{P}=0.026)$. In addition, there was no significant difference in death/survival numbers between the low citrate group and the high citrate group $(\mathrm{p}>0.05)$ (Table 1$)$.

Comparing different variables recorded in the end of CRRT between the two levels of TBil

Different variables recorded in the end of CRRT were compared between the low TBil group and the high TBil group (Table 3 ). The variables included $\mathrm{tCa}$ /iCa ratio, circuit survival time, blood pressure, TMP, $\mathrm{pH}$, lactates, sodium and magnesium. No significant difference was found in the above variables except for lactates. The lactates levels in the high TBil group were significantly higher than that in the low TBil group $(\mathrm{p}=0.018)$, with medians of 1.67 $(1.10 ; 2.26) \mathrm{mmol} / \mathrm{L}$ and $1.30(0.93 ; 1.80) \mathrm{mmol} / \mathrm{L}$ respectively. In addition, there was no significant difference in death/survival numbers between the low TBil group and the high TBil group ( $\mathrm{p}>0.05)$ (Table 1).
Table 2. Comparing different variables recorded at the end of CRRT pressure. *Low citrate group: Cases with $\mathrm{tCa} / \mathrm{iCa}$ ratio $<2.1$. ${ }^{*} \mathrm{High}$ citrate group: Cases with $\mathrm{tCa} / \mathrm{iCa}$ ratio $\geq 2.1$. ${ }^{*} \mathrm{P}$ value: Mann-WhitneyWilcoxon test was applied to compare each variable between the two groups. ${ }^{* *} \mathrm{P}<0.05$

\begin{tabular}{lccc}
\hline Parameter & $\begin{array}{c}\text { Low citrate group* } \\
\text { [median(quartiles)] }\end{array}$ & $\begin{array}{c}\text { High citrate group* } \\
\text { [median(quartiles)] }\end{array}$ & $\begin{array}{c}\text { P } \\
\text { value* }^{*}\end{array}$ \\
\hline Circuit survival time (hour) & $47.50(37.75 ; 58.58)$ & $40.25(31.01 ; 53.81)$ & $0.026^{* *}$ \\
pH & $7.41(7.37 ; 7.45)$ & $7.41(7.38 ; 7.47)$ & 0.273 \\
Lactate (mmol/L) & $1.50(1.00 ; 1.90)$ & $1.40(1.00 ; 2.18)$ & 0.835 \\
Sodium (mmol/L) & $137(136 ; 140)$ & $138(136 ; 140)$ & 0.431 \\
Magnesium (mmol/L) & $0.77(0.69 ; 0.87)$ & $0.76(0.70 ; 0.84)$ & 0.774 \\
Systolic pressure (mmHg) & $130(114 ; 144)$ & $136(118 ; 147)$ & 0.240 \\
Diastolic pressure (mmHg) & $67(56 ; 77)$ & $65(56 ; 78)$ & 0.982 \\
TMP* (mmHg) & $246(194 ; 292)$ & $245(212 ; 280)$ & 0.823 \\
Case number & 85 & 60 & \\
\hline
\end{tabular}




\section{Kidney Blood Pressure Research}

Kidney Blood Press Res 2018;43:1065-1074

DOI: 10.1159/000491057

Published online: 2 July, 2018

(C) 2018 The Author(s). Published by S. Karger AG, Basel www.karger.com/kbr
Table 3. Comparing different variables recorded at the end of CRRT between the two levels of TBil. TMP: Trans-membrane pressure. *Low TBil group: Cases with total bilirubin level $<13.20 \mu \mathrm{mol} / \mathrm{L}$. *High TBil group: Cases with total bilirubin level $\geq 13.20 \mu \mathrm{mol} / \mathrm{L}$. ${ }^{*} \mathrm{P}$ value: Mann-Whitney-Wilcoxon test was applied to compare each variable between the two groups. ${ }^{* *} \mathrm{P}<0.05$

\begin{tabular}{lccc}
\hline Parameter & $\begin{array}{c}\text { Low TBil group* } \\
\text { [median(quartiles)] }\end{array}$ & $\begin{array}{c}\text { High TBil group* } \\
\text { [median(quartiles)] }\end{array}$ & P value* \\
\hline tCa/iCa ratio & $2.08(1.95 ; 2.22)$ & $2.04(1.91 ; 2.17)$ & 0.274 \\
Circuit survival time (hour) & $44.53(34.75 ; 58.16)$ & $43.30(36.00 ; 52.62)$ & 0.809 \\
pH & $7.41(7.38 ; 7.46)$ & $7.41(7.37 ; 7.46)$ & 0.785 \\
Lactate (mmol/L) & $1.30(0.93 ; 1.80)$ & $1.67(1.10 ; 2.26)$ & $0.018^{* *}$ \\
Sodium (mmol/L) & $137(136 ; 140)$ & $138(136 ; 140)$ & 0.956 \\
Magnesium (mmol/L) & $0.76(0.68 ; 0.85)$ & $0.77(0.71 ; 0.87)$ & 0.393 \\
Systolic pressure (mmHg) & $134(118 ; 150)$ & $129(113 ; 140)$ & 0.235 \\
Diastolic pressure (mmHg) & $67(56 ; 77)$ & $64(57 ; 77)$ & 0.738 \\
TMP* (mmHg) & $239(192 ; 280)$ & $258(218 ; 291)$ & 0.119 \\
Case number & 72 & 73 & \\
\hline
\end{tabular}

Table 4. Comparing different variables recorded at the end of CRRT between the two levels of INR. *TMP: Trans-membrane pressure. *Low INR group: Cases with international normalized ratio<1.29. *High INR group: Cases with international normalized ratio $\geq 1.29$. ${ }^{*} \mathrm{P}$ value: Mann-WhitneyWilcoxon test was applied to compare each variable between the two groups. ${ }^{* *} \mathrm{P}<0.05$

\begin{tabular}{lccc}
\hline Parameter & $\begin{array}{c}\text { Low INR group* } \\
\text { [median(quartiles)] }\end{array}$ & $\begin{array}{c}\text { High INR group* } \\
\text { [median(quartiles)] }\end{array}$ & P value* \\
\hline tCa/iCa ratio & $2.06(1.92 ; 2.22)$ & $2.07(1.93 ; 2.21)$ & 0.611 \\
Circuit survival time (hour) & $44.96(35.04 ; 53.60)$ & $43.50(36.00 ; 57.75)$ & 0.907 \\
pH & $7.41(7.37 ; 7.46)$ & $7.41(7.37 ; 7.45)$ & 0.452 \\
Lactate $(\mathrm{mmol} / \mathrm{L})$ & $1.26(0.90 ; 1.64)$ & $1.80(1.23 ; 2.43)$ & $<0.001^{* *}$ \\
Sodium $(\mathrm{mmol} / \mathrm{L})$ & $137(136 ; 140)$ & $138(136 ; 140)$ & 0.527 \\
Magnesium $(\mathrm{mmol} / \mathrm{L})$ & $0.79(0.70 ; 0.87)$ & $0.75(0.68 ; 0.84)$ & 0.150 \\
Systolic pressure $(\mathrm{mmHg})$ & $135(121 ; 150)$ & $128(110 ; 138)$ & $0.013^{* *}$ \\
Diastolic pressure $(\mathrm{mmHg})$ & $69(57 ; 79)$ & $63(56 ; 73)$ & $0.043^{* *}$ \\
TMP* $(\mathrm{mmHg})$ & $252(218 ; 284)$ & $241(192 ; 283)$ & 0.305 \\
Case number & 72 & 73 & \\
\hline \multicolumn{4}{c}{} \\
\hline
\end{tabular}

Comparing different variables recorded in the end of CRRT between the two levels of INR

Different variables recorded at the end of CRRT were compared between the low INR group and the high INR group (Table 4). The variables included tCa/iCa ratio, circuit survival time, blood pressure, TMP, pH, lactates, sodium and magnesium. No significant difference was found in the above variables except for lactates and blood pressure. The lactates levels in the high INR group were significantly higher than that in the low INR group $(p<0.001)$, with medians of $1.80(1.23 ; 2.43) \mathrm{mmol} / \mathrm{L}$ and $1.26(0.90 ; 1.64) \mathrm{mmol} / \mathrm{L}$ respectively. The systolic pressure levels in the high INR group were significantly lower than that in the low INR group ( $p=0.013)$, with medians of $128(110 ; 138) \mathrm{mmHg}$ and $135(121 ; 150) \mathrm{mmHg}$ respectively. The diastolic pressure levels in the high INR group were also significantly lower than that in the low INR group ( $\mathrm{p}=0.043)$, with medians of $63(56 ; 73) \mathrm{mmHg}$ and $69(57 ; 79) \mathrm{mmHg}$ respectively. In addition, there was no significant difference in death/survival numbers between the low INR group and the high INR group ( $\mathrm{p}>0.05)$ (Table 1).

\section{Discussion}

We have shown in the present study that, with proper monitoring and adjustment of citrates and calcium infusion, applying RCA in CRRT is reasonably safe for AKI patients with acute liver dysfunction, as long as circuit time stays below roughly 50 hours.

In 2012, the use of citrates for the anticoagulation in CRRT has been recommended by KDIGO guidelines [2], mainly on the basis of a large randomized controlled trial involving 200 patients, which showed that citrate anticoagulation was associated with fewer complications (e.g. bleeding and thrombocytopenia) [14]. However, liver diseases were deemed as contraindications, according to the theory that the metabolism of citrates is impaired in patients with liver dysfunction, which could elevate the risk of citrates accumulation. Thus heparin was suggested to be applied as the anticoagulant for patients with liver disease.

Yet heparin could generate unpredictable effects by binding with nonspecific substances. By binding with antithrombin, it confers its anticoagulant effect. But by binding either with apoptotic cells, necrotic cells, or acute phase proteins, it may interfere with the microcirculation, inflammation pathways, and the phagocytotic clearance of dead cells. Especially under critical situations like sepsis or systemic inflammation, heparin could cause antithrombin consumption and degradation, as well as deleterious consequences due to the above reasons [10]. 


\section{Kidney Blood Pressure Research}

Kidney Blood Press Res 2018;43:1065-1074

DOI: $10.1159 / 000491057$

Published online: 2 July, 2018

(c) 2018 The Author(s). Published by S. Karger AG, Basel www.karger.com/kbr

Patients with liver dysfunction may be accompanied by pathological changes like hyperfibrinolysis, accelerated intravascular coagulation, defected platelet (quantitatively and qualitatively), decreased synthesis of procoagulant and anticoagulant factors, as well as decreased clearance of activated factors [26,27]. These pathological changes could contribute to developing hemorrhagic complications when using any type of extracorporeal support with systemic anticoagulation. In such situations, heparin is not an ideal anticoagulant. Thus the present study was designed to verify that whether applying RCA in CRRT for patients with acute liver dysfunction would result in the assumed complications or adverse outcomes.

In normal serum protein concentrations, total serum calcium is comprised of approximately $50 \%$ of ionized form $\left(\mathrm{Ca}^{2+}\right), 8 \%-10 \%$ of acid-complexed form (complexed to organic and inorganic acids as citrates, sulphates and phosphates), and the remaining $40 \%$ of protein-bound form ( $80 \%$ to albumins, $20 \%$ to globulins)[28]. To estimate the accumulation degree of citrates, iCa is a sensitive indicator, but not adequately specific and could be related to other causes [29]. Whereas, the increase of $\mathrm{tCa} / \mathrm{iCa}$ ratio correlates best with plasma citrates level [30]. Therefore, $\mathrm{tCa} / \mathrm{iCa}$ ratio was calculated to assess the accumulation degree of citrates in our study.

Some studies have reported or applied different cut-offs of tCa/iCa ratio to define citrates overdose, e.g.2.1 [31, 32], 2.25 [33], 2.4 [34], 2.5 [23, 29, 35, 36]. Mostly the ratio of 2.1 and 2.5 are being used. However, the theory of using 2.5 as the cut-off ratio was simply based on a case report on one patient [29], while using 2.1 was based on a study enrolling 10 patients, and specifically with the definition of citrates overdose as citrates concentration $>1.0 \mathrm{mmol} / \mathrm{L}$ [32]. Thus the ratio of 2.1 was set as the cut-off value in our study to divide the cases into the high citrate group and the low citrate group.

The study of Faybik P. et al. which involved 20 patients have demonstrated an increase of tCa/iCa ratios (2.04 \pm 0.32 to $2.17 \pm 0.35 ; \mathrm{p}=0.01$ ) in patients with liver failure [19]. However, our study showed that neither did TBil nor INR (indicating the residual liver function) interfere with the $\mathrm{tCa} / \mathrm{iCa}$ ratio. And there was no correlation of the $\mathrm{tCa} / \mathrm{iCa}$ ratio with $\mathrm{TBil}$ or INR. These could be explained by the sufficient and timely supplement of calcium. In addition, it's possible that the liver function was improved during CRRT. And some reports have indicated that the kidney musculature also appears to remove citrates in blood [20,37].

The accumulation of citrates was reported to be associated with metabolic derangements like hypocalcemia, hypernatremia, hyponatremia, metabolic alkalosis and acidosis [10], as well as hypomagnesemia [33]. The molecule citrate itself is not toxic, but the accumulation of it could induce ionized hypocalcemia in the systemic circulation. Because in extracellular fluid, increases of anions such as citrates, phosphates, bicarbonates, or edetic acids, could chelate calcium and reduce the concentration of ionized calcium, but maintaining the concentration of total serum calcium [38]. Ionized calcium is the biologically active form. Ionized hypocalcemia may lead to decreased cardiac contractility and hypotension [39-41].

Yet, the results in our study showed that neither was the accumulation degree of citrates nor TBil associated with hypotension. However, the reason that INR was associated with hypotension might be the patients with lower blood pressure were likely to be in worse status of blood circulation, and more likely to develop disseminated intravascular coagulation (DIC), which could interfere with INR level.

Besides hypotension, acid-base derangements were also reported to be the results of citrates accumulation. Metabolic acidosis could be the result of large doses of citrates not being metabolized; metabolic alkalosis could be the result of mass delivering of sodium citrates (eg. accidentally rapid infusion or protocol violation); hypernatremia could be the result of the sodium not being reduced proportionally in the solution, leaving the unopposed sodium [42-44]; hypomagnesemia could be the result of citrates binding to $\mathrm{Mg}^{2+}$ [33].

However, the results of our study showed that neither did the accumulation degree of citrates nor the severity of liver dysfunction interfere with serum $\mathrm{pH}$ values, or concentrations of $\mathrm{Na}^{+}$or $\mathrm{Mg}^{2+}$. This was consistent with the study led by Schultheiss C. et al. demonstrating 7 out of 43 runs of continuous venovenous hemodialysis (CVVHD) using CRA on liver failure 


\section{Kidney Blood Pressure Research}

patients, with $\mathrm{tCa}$ /iCa ratios 10 times exceeding the threshold (the threshold was set as $\mathrm{tCa}$ / iCa ratio $\geq 2.5$ ), yet have finished without major disturbances of acid-base or electrolyte status [23]. Kramer L. et al.'s study showed similar results by comparing 16 critically ill cirrhotic patients with 16 non-cirrhotic patients, demonstrating quantitatively similar net metabolic changes and noting no citrate-related side effects [22].

In addition, the $\mathrm{tCa} / \mathrm{iCa}$ ratio did not interfere with serum lactates levels. However, patients with higher TBil and INR appeared higher lactates levels. This might be because that lactate is an index to indicate the status of systematic blood perfusion. And poor systematic blood perfusion could lead to poor residual liver function. Therefore, it's natural that TBil and INR showed an association with lactates levels.

Circuit survival time is another factor to consider when choosing anticoagulants for CRRT. The longer it lasts, the better consistency of therapy is gained, which means the better efficacy with less costs. The circuit survival time in our study appeared to be very low because many circuits were stopped for transferring patients to take image exams. Also, the cohort of this study consisted of patients with relatively high APACHE II scores. Thus the proportion of death or abandonment of treatment was relatively high. Although the circuit survival time in our study was affected by the accumulation degree of citrates, it was not affected by liver dysfunction levels. This was in accordance with the study led by Balogun R. A. et al., which enrolled 697 patients using RCA in CRRT and demonstrated no significant difference in circuit survival time among varying severities of liver dysfunction [21].

Moreover, our results indicated that neither were the accumulation degrees of citrates nor liver dysfunction levels related with fatal outcomes, which could be the result of the sufficient monitoring and adjustment of citrates and calcium infusion. In a way, it suggested that in clinical practice, even the assumed 'overdose' of citrates was not related with the fatal outcome. This further supported that using RCA in CRRT is reasonably safe for patients with acute liver dysfunction with proper monitoring and adjustment of citrates and calcium infusion.

\section{Conclusion}

In AKI patients with acute liver dysfunction who received CRRT with RCA, our study demonstrated that, with proper monitoring and adjustment of citrates and calcium infusion, using RCA in CRRT is reasonably safe for patients with liver dysfunction, as long as circuit time stays below roughly 50 hours.

\section{Acknowledgements}

This work was supported by the Science and Technology Planning Project of Guangdong Province (2014A020212203) and the Science and Technology Planning Project of Guangdong Province (2017ZC0111). The funders had no role in study design, data collection and analysis, decision to publish, or preparation of the manuscript.

We appreciate all coworkers in ICU of Zhujiang Hospital who contributed to this research.

YY analyzed and interpreted the data, and was a major contributor in writing the manuscript. SP was a major contributor in collecting and interpreting the data. SP, ZC, JC, WW, YT, MD co-designed this study and collected the data. PC was a major contributor in designing and instructing this project. All authors read and approved the final manuscript. 


\section{Kidney Blood Pressure Research}

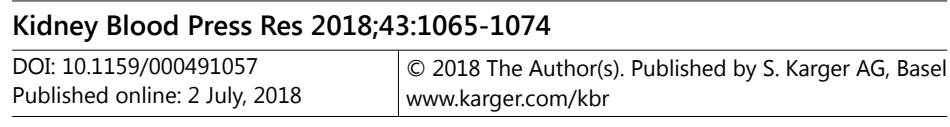

Yu et al.: Study of RCA in CRRT for AKI Patients with Acute Liver Dysfunction

\section{Disclosure Statement}

The authors declare that there is no conflict of interest associated with this manuscript.

\section{References}

1 Uchino S, Kellum JA, Bellomo R, Doig GS, Morimatsu H, Morgera S, Schetz M, Tan I, Bouman C, Macedo E, Gibney N, Tolwani A, Ronco C: Acute renal failure in critically ill patients: a multinational, multicenter study. JAMA 2005;294:813-818.

-2 Khwaja A: Kdigo clinical practice guidelines for acute kidney injury. Nephron Clin Pract 2012;120:C179-C184.

3 Schneider AG, Bellomo R, Bagshaw SM, Glassford NJ, Lo S, Jun M, Cass A, Gallagher M: Choice of renal replacement therapy modality and dialysis dependence after acute kidney injury: a systematic review and meta-analysis. Intensive Care Med 2013;39:987-997.

-4 Wald R, Shariff SZ, Adhikari NKJ, Bagshaw SM, Burns KEA, Friedrich JO, Garg AX, Harel Z, Kitchlu A, Ray JG: The association between renal replacement therapy modality and long-term outcomes among critically ill adults with acute kidney injury: a retrospective cohort study. Crit Care Med 2014;42:868-877.

5 Srisawat N, Lawsin L, Uchino S, Bellomo R, Kellum JA: Cost of acute renal replacement therapy in the intensive care unit: results from the beginning and ending supportive therapy for the kidney (best kidney) study. Crit Care 2010;14:R46.

-6 Manns B, Doig CJ, Lee H, Dean S, Tonelli M, Johnson D, Donaldson C: Cost of acute renal failure requiring dialysis in the intensive care unit: clinical and resource implications of renal recovery. Crit Care Med 2003;31:449-455.

7 Rewa 0, Villeneuve PM, Eurich DT, Stelfox HT, Gibney RT, Hartling L, Featherstone R, Bagshaw SM: Quality indicators in continuous renal replacement therapy (crrt) care in critically ill patients: protocol for a systematic review. Syst Rev 2015;4:102.

8 Tolwani A: Continuous renal-replacement therapy for acute kidney injury. New Engl J Med 2012;367:25052514.

-9 Hirsh J, Warkentin TE, Raschke R, Granger C, Ohman EM, Dalen JE: Heparin and low-molecular-weight heparin: mechanisms of action, pharmacokinetics, dosing considerations, monitoring, efficacy, and safety. Chest 1998;114:489S-510S.

10 Oudemans-van Straaten HM, Kellum JA, Bellomo R: Clinical review: anticoagulation for continuous renal replacement therapy - heparin or citrate? Crit Care 2011;15:202.

11 Lanckohr C, Hahnenkamp K, Boschin M: Continuous renal replacement therapy with regional citrate anticoagulation: do we really know the details? Curr Opin Anaesthesiol 2013;26:428-437.

12 Tolwani A, Wille KM: Advances in continuous renal replacement therapy: citrate anticoagulation update. Blood Purif 2012;34:88-93.

13 Hetzel GR, Schmitz M, Wissing H, Ries W, Schott G, Heering PJ, Isgro F, Kribben A, Himmele R, Grabensee B, Rump LC: Regional citrate versus systemic heparin for anticoagulation in critically ill patients on continuous venovenous haemofiltration: a prospective randomized multicentre trial. Nephrol Dial Transplant 2011;26:232-239.

14 Oudemans-van Straaten HM, Bosman RJ, Koopmans M, van der Voort PHJ, Wester JPJ, van der Spoel JI, Dijksman LM, Zandstra DF: Citrate anticoagulation for continuous venovenous hemofiltration. Crit Care Med 2009;37:545-552.

15 Morabito S, Pistolesi V, Tritapepe L, Zeppilli L, Polistena F, Strampelli E, Pierucci A: Regional citrate anticoagulation in cardiac surgery patients at high risk of bleeding: a continuous veno-venous hemofiltration protocol with a low concentration citrate solution. Crit Care 2012;16:R111.

16 Apsner R, Schwarzenhofer M, Derfler K, Zauner C, Ratheiser K, Kranz A: Impairment of citrate metabolism in acute hepatic failure. Wien Klin Wochenschr 1997;109:123-127.

17 Simpson DP: Citrate excretion: a window on renal metabolism. Am J Physiol 1983;244:F223-F234. 


\section{Kidney \\ Blood Pressure Research}

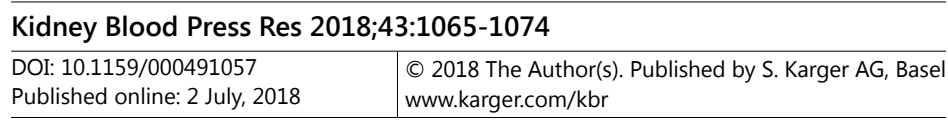

Yu et al.: Study of RCA in CRRT for AKI Patients with Acute Liver Dysfunction

18 Bauer E, Derfler K, Joukhadar C, Druml W: Citrate kinetics in patients receiving long-term hemodialysis therapy. Am J Kidney Dis 2005;46:903-907.

19 Faybik P, Hetz H, Mitterer G, Krenn CG, Schiefer J, Funk GC, Bacher A: Regional citrate anticoagulation in patients with liver failure supported by a molecular adsorbent recirculating system. Crit Care Med 2011;39:273-279.

20 Chen C, Ye C: Regional anticoagulation with citrate for maintenance haemodialysis in a patient with liver cirrhosis for 30 months. Nephrology (Carlton) 2011;16:786-787.

21 Balogun RA, Turgut F, Caldwell S, Abdel-Rahman EM: Regional citrate anticoagulation in critically ill patients with liver and kidney failure. J Nephrol 2012;25:113-119.

-22 Kramer L, Bauer E, Joukhadar C, Strobl W, Gendo A, Madl C, Gangl A: Citrate pharmacokinetics and metabolism in cirrhotic and noncirrhotic critically ill patients. Crit Care Med 2003;31:2450-2455.

23 Schultheiss C, Saugel B, Phillip V, Thies P, Noe S, Mayr U, Haller B, Einwaechter H, Schmid RM, Huber W: Continuous venovenous hemodialysis with regional citrate anticoagulation in patients with liver failure: a prospective observational study. Crit Care 2012;16:R162.

-24 De Vico P, Messino V, Tartaglione A, Beccaris C, Buonomo C, Talarico D, Prati P, Sabato AF, Colella DF: Safety and efficacy of citrate anti-coagulation continuous renal replacement therapies in post-cardiac surgery patients with liver dysfunction. Ther Apher Dial 2015;19:272-278.

25 Bakker AJ, Boerma EC, Keidel H, Kingma P, van der Voort PH: Detection of citrate overdose in critically ill patients on citrate-anticoagulated venovenous haemofiltration: use of ionised and total/ionised calcium. Clin Chem Lab Med 2006;44:962-966.

-26 Amitrano L, Guardascione MA, Brancaccio V, Balzano A: Coagulation disorders in liver disease. Semin Liver Dis 2002;22:83-96.

-27 Wada H, Usui M, Sakuragawa N: Hemostatic abnormalities and liver diseases. Semin Thromb Hemost 2008;34:772-778.

-28 Moore EW: Ionized calcium in normal serum, ultrafiltrates, and whole blood determined by ion-exchange electrodes. J Clin Invest 1970;49:318-334.

29 Meier-Kriesche HU, Finkel KW, Gitomer JJ, DuBose TDJ: Unexpected severe hypocalcemia during continuous venovenous hemodialysis with regional citrate anticoagulation. Am J Kidney Dis 1999;33:e8.

-30 Hetzel GR, Taskaya G, Sucker C, Hennersdorf M, Grabensee B, Schmitz M: Citrate plasma levels in patients under regional anticoagulation in continuous venovenous hemofiltration. Am J Kidney Dis 2006;48:806811.

31 Khadzhynov D, Schelter C, Lieker I, Mika A, Staeck O, Neumayer HH, Peters H, Slowinski T: Incidence and outcome of metabolic disarrangements consistent with citrate accumulation in critically ill patients undergoing continuous venovenous hemodialysis with regional citrate anticoagulation. J Crit Care 2014;29:265-271.

32 Bakker AJ, Boerma EC, Keidel H, Kingma P, van der Voort PHJ: Detection of citrate overdose in critically ill patients on citrate-anticoagulated venovenous haemofiltration: use of ionised and total/ionised calcium. Clin Chem Lab Med 2006;44:962-966.

-33 Oudemans-van Straaten HM, Ostermann M: Bench-to-bedside review: citrate for continuous renal replacement therapy, from science to practice. Crit Care 2012;16:249.

-34 Link A, Klingele M, Speer T, Rbah R, Poess J, Lerner-Graeber A, Fliser D, Boehm M: Total-to-ionized calcium ratio predicts mortality in continuous renal replacement therapy with citrate anticoagulation in critically ill patients. Crit Care 2012;16:R97.

-35 Meier-Kriesche HU, Gitomer J, Finkel K, DuBose T: Increased total to ionized calcium ratio during continuous venovenous hemodialysis with regional citrate anticoagulation. Crit Care Med 2001;29:748752.

-36 Slowinski T, Morgera S, Joannidis M, Henneberg T, Stocker R, Helset E, Andersen K, Wehner M, KozikJaromin I, Brett S, Hasslacher I, Stover JF, Peters H, Neumayer HH, Kindgen-Milles D: Multicenter prospective observational study on safety and efficacy of regional citrate anticoagulation in CVVHD in presence of liver failure: the liver citrate anticoagulation threshold study (l-cat). Crit Care 2011;15:P127.

-37 Wexler IB, Pincus JB, Natelson S, Lugovoy JK: The fate of citrate in erythroblastotic infants treated with exchange transfusion. J Clin Invest 1949;28:474-481.

-38 Kelly A, Levine MA: Hypocalcemia in the critically ill patient. J Intensive Care Med 2013;28:166-177. 


\section{Kidney Research}

-39 Zaloga GP, Chernow B: The multifactorial basis for hypocalcemia during sepsis. Studies of the parathyroid hormone-vitamin d axis. Ann Intern Med 1987;107:36-41.

40 Desai TK, Carlson RW, Thill-Baharozian M, Geheb MA: A direct relationship between ionized calcium and arterial pressure among patients in an intensive care unit. Crit Care Med 1988;16:578-582.

41 Ghent S, Judson MA, Rosansky SJ: Refractory hypotension associated with hypocalcemia and renal disease. Am J Kidney Dis 1994;23:430-432.

-42 Oudemans-van Straaten HM, Ostermann M: Bench-to-bedside review: citrate for continuous renal replacement therapy, from science to practice. Crit Care 2012;16:249.

-43 Mehta RL, McDonald BR, Aguilar MM, Ward DM: Regional citrate anticoagulation for continuous arteriovenous hemodialysis in critically ill patients. Kidney Int 1990;38:976-981.

44 Diaz J, Acosta F, Parrilla P, Sansano T, Contreras RF, Bueno FS, Martinez P: Correlation among ionized calcium, citrate, and total calcium levels during hepatic transplantation. Clin Biochem 1995;28:315-317. 